\title{
ANÁLISIS
}

\section{FILMOTECAS EN LA ENCRUCIJADA. FUNCIÓN Y EXPANSIÓN DE LA ACTIVIDAD FILMOTECARIA EN EL NUEVO ESCENARIO DIGITAL}

\section{Pablo García-Casado y Jordi Alberich-Pascual}

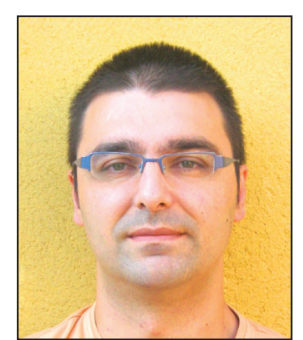

Pablo García-Casado, Córdoba, 1972, es licenciado en derecho por la Universidad de Córdoba (UCO) y máster en gestión de instituciones y empresas culturales por la Universidad de Barcelona. Máster de cinematografía por la UCO. Ha desarrollado su labor en la gestión cultural en diversos ámbitos, entre los que destacan, entre otros, la coordinación del Programa arte y creación joven de la Junta de Andalucía o formar parte del equipo de redacción de la candidatura de Córdoba a Capital cultural europea 2016. Desde 2008 dirige la Filmoteca de Andalucía. http://orcid.org/0000-0001-6685-1957

Filmoteca de Andalucía Medina y Corella, 5. 14003 Córdoba, España pablo.garcia@juntadeandalucia.es

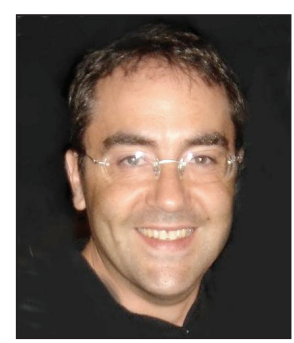

Jordi Alberich-Pascual, La Bisbal de Falset, Tarragona, 1969, doctor por la Universidad de Barcelona (1998), es profesor titular de universidad de comunicación audiovisual y publicidad en la Facultad de Comunicación y Documentación de la Universidad de Granada. Ha desarrollado su actividad investigadora como experto en estética y cultura audiovisual digital. Es miembro del laboratorio de investigación Secaba, e investigador colaborador del grupo de investigación SCI2S (Soft Computing and Intelligent Information Systems) y del Internet Interdisciplinary Institute (IN3), centro de investigación de excelencia de la Universitat Oberta de Catalunya.

http://orcid.org/0000-0001-6871-4614

Universidad de Granada Facultad de Comunicación y Documentación, Departamento de Información y Comunicación Campus Cartuja, s/n. 18071 Granada, España jalberich@ugr.es

\section{Resumen}

El intenso cambio digital que está atravesando el mundo del cine plantea importantes retos de futuro a las filmotecas. En este artículo revisamos hasta qué punto las bases que fundaron la actividad filmotecaria en los años treinta del siglo pasado siguen vigentes en plena sociedad de la información, así como los principales debates que cuestionan su identidad y función en pleno siglo XXI. Exploramos para ello las líneas de expansión que se dibujan en el actual escenario digital para el campo filmotecario, y ofrecemos finalmente respuesta a las encrucijadas a las que se enfrentan hoy las filmotecas si éstas no quieren quedar aisladas.

\section{Palabras clave}

Filmotecas, Archivos fílmicos, Patrimonio fílmico, Cine digital, Accesibilidad.

Title: Film archives at the crossroads. Function and expansion of film archive activity in the new digital landscape

\section{Abstract}

The intense digital change that is taking place in the world of cinema presents significant future challenges for film archives. This article reviews the extent to which the basis for the activities of film libraries founded in the 1930s remains valid in the information age, along with key debates questioning their identity and role in the 21st century. We explore the lines of film archives expansion that are being drawn in the current digital context, and finally offer a response to the crossroads that film libraries face today if they do not want to become isolated.

\section{Keywords}

Film libraries, Film archives, Film heritage, Digital cinema, Accessibility.

García-Casado, Pablo; Alberich-Pascual, Jordi (2014). "Filmotecas en la encrucijada. Función y expansión de la actividad filmotecaria en el nuevo escenario digital". El profesional de la información, enero-febrero, v. 23, n. 1, pp. 59-64.

http://dx.doi.org/10.3145/epi.2014.ene.07 


\section{Introducción}

¿Para qué sirve una filmoteca en pleno siglo XXI? ¿Hasta qué punto las bases que las fundaron en los años treinta del siglo pasado siguen vigentes en plena era digital, con la existencia del inmenso aluvión de imágenes en movimiento que se generan a cada instante en el mundo? Aunque para apreciar en toda su intensidad el Phantom (1922) de Friedrich W. Murnau debamos acudir sin duda a la restauración que de ésta hizo Luciano Berriatúa ${ }^{1}$ y visionar la copia en una sala semejante a las condiciones de su primera proyección, hoy en día cualquiera puede teclear en Google este título y ver-aunque pixelada y en baja calidad- una de estas joyas de los pioneros del cine.

El nuevo escenario digital ha transformado de forma radical el quehacer diario de las filmotecas. El intercambio de archivos cinematográficos y el flujo entre particulares es un hecho gracias a las nuevas tecnologías. Investigadores e interesados por el cine prefieren acudir cada vez más a una ventana en la Red, a un archivo compartido o a una pieza en streaming, antes que desplazarse hasta un archivo fílmico. Las propias filmotecas han empezado a poner en internet parte de sus fondos, bien con fines comerciales, divulgativos o incluso educativos, tal y como ejemplifican los casos de la Cinémathèque Française a través de la plataforma Dailymotion $^{2}$, del canal propio de exhibición de películas de corte experimental y de muestras de archivos restaurados del EYE Film Institute de Amsterdam ${ }^{3}$, o el volcado a la red por parte de la Filmoteca Española de una parte del archivo NO$D O^{4}$, así como de parte de sus fondos sobre la Guerra Civil Española en el Canal Cultura de YouTube del Ministerio de Educación, Cultura y Deporte de España 5 .

Desde sus inicios, quienes abordaban la tarea de hacer cine se planteaban qué hacer con todo ese material generado; dispositivos necesarios para la magia, pero que una vez cumplido su ciclo de explotación comercial se convertían en una suerte de basura tecnológica. Por eso ha sido y es una constante desde que nació el cine la destrucción sistemática de las copias. Se estima habitualmente que más del $80 \%$ de

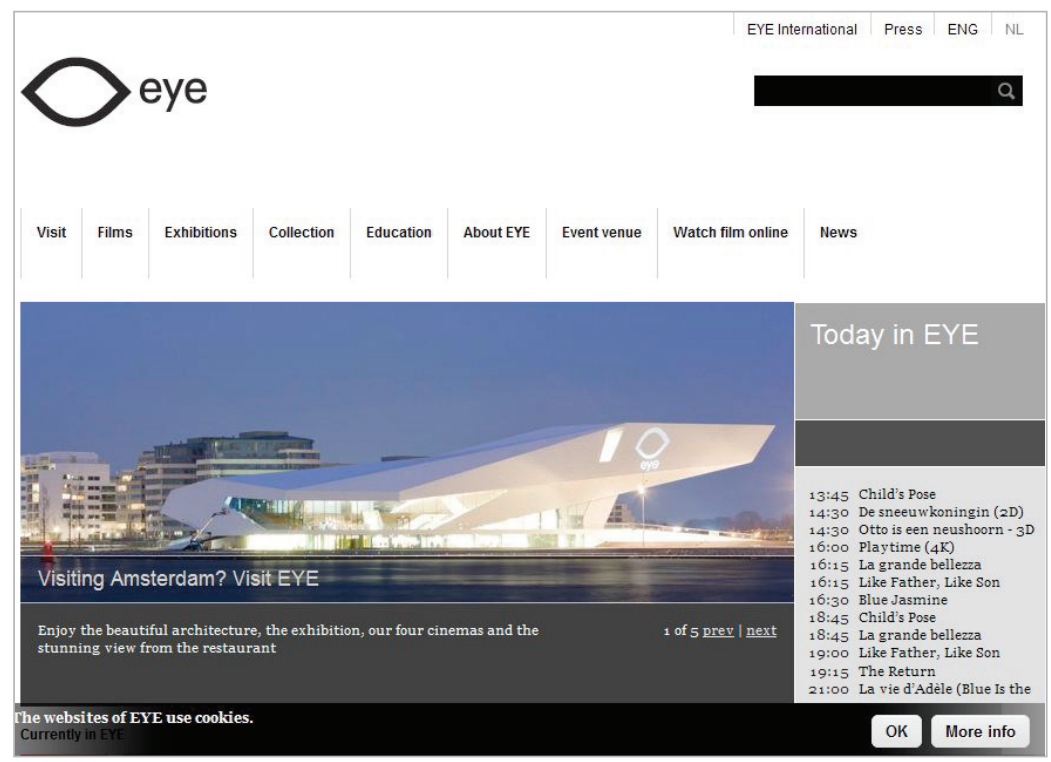

http://www.eyefilm.nl/en la producción fílmica de los primeros veinte años de vida del cinematógrafo acabaron destruidos (Borde, 1991, p. 13). La destrucción ha sido connatural al hecho cinematográfico, y lo sigue siendo hoy mismo.

La misión de las filmotecas debe ser incorporarse hoy a esa ola de accesibilidad, pero salvaguardando los valores de excelencia cinematográfica

Frente a esta realidad nacieron precisamente las filmotecas, unas instituciones destinadas a conjurar "la tristeza dulce de los objetos fabricados en serie" (Gimferrer, 1998, p. 8), y que pese a que no han gozado del crédito moral e intelectual de otras instituciones culturales hermanas como museos o bibliotecas, han constituido un baluarte ante una industria que tiene sus propios ritmos económicos contrarios a la conservación fílmica: "Como productos de la industria cultural las obras cinematográficas, las películas, gozan del privilegio de la conservación, pero como productos de la industria del espectáculo, sólo valen mientras rinden beneficios" (Del-Amo, 2011, p. 14).

El presente artículo tiene así como objetivo específico dar respuesta a los retos y encrucijadas a las que se enfrentan las filmotecas en el actual escenario digital, y que cuestionan su identidad y función en pleno siglo XXI.

\section{La actividad filmotecaria mas allá de la dicotomía archivo-exhibición}

Dos maneras contrapuestas de entender el fenómeno filmotecario, resumidas en la dicotomía archivo-exhibición, han definido la actividad de esas instituciones. A partir del congreso de la Federación Internacional de Archivos Fímicos (FIAF) celebrado en Copenhague (1948) se evidencian dos modelos contrapuestos que articulan la función e identidad de las filmotecas a lo largo del tiempo. El primero lo abanderó el director del British Film Institute durante casi cuarenta años, Ernest Lindgren (1910-1973), para quien la prioridad de un archivo fílmico era conservar los films frente a la descomposición química y el abuso del tráfico. El segundo modelo apareció personificado en Henri Langlois (1914-1977), fundador de la Cinémathèque Française en 1936, que planteó que la principal tarea de una filmoteca es la difusión de la cultura a través del cine.

El porqué de esta dicotomía Lindgren-Langlois cabe buscarlo en el origen de las dos instituciones que dirigía cada uno. Así, el $B F I$ es un servicio público creado a instancias de la Commons Chamber en 1933. Su identidad es vocacionalmente archivística y de optimización de la conservación física de un material frágil, volátil y perecedero. Se trata, en palabras del propio Lindgren, "de conservar a perpetuidad el interés nacio- 
nal" (Borde, 1991, p. 55). Frente a este modelo, la Cinémathèque Française nació de un cine-club, una asociación privada destinada a la difusión de films de repertorio. La existencia y la acumulación de metros y metros de película sólo tiene sentido en aras de su proyección. Los aspectos de conservación para Langlois y su equipo quedaban así en un segundo plano.

Esta dialéctica no pacífica, trufada de relaciones personales de admiración y reproche se sustanció además en el perfil humano de los oponentes. Lindgren, según

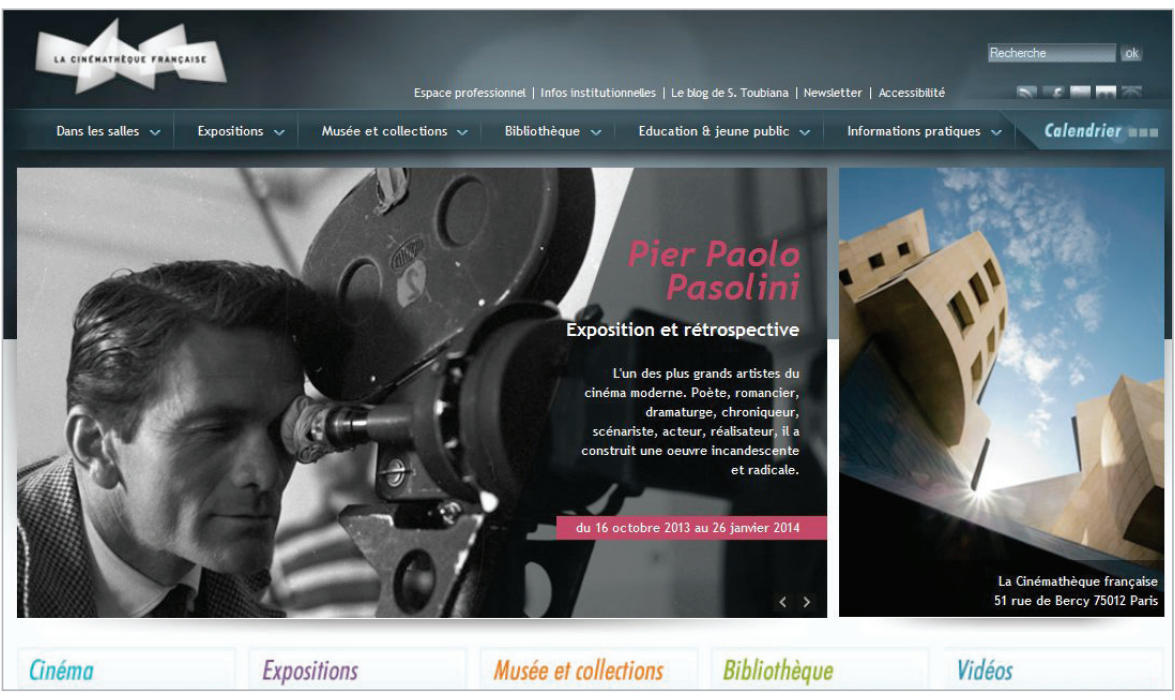

http://www.cinematheque.fr sus propias palabras, se consideró "una mente científica, pragmática, orgullosa de lo que sale de los laboratorios" (Beale, 2011 , p. 10). Langlois era por contra un hombre del espectáculo, alguien que rechaza el elitismo intelectual, que prefiere una ósmosis entre la alta cultura y la cultura de masas, y que no tenía dudas en proyectar para los cinéfilos de su entorno las películas que adquiría ${ }^{6}$, pese al riesgo de poner en peligro su conservación a largo plazo.

Desgraciadamente, la dicotomía archivo-exhibición está lejos de quedar superada. Son muestras de ello tanto la emergencia reciente del manifiesto que recoge las propuestas del inglés y las pone en actualidad bajo el nombre de "Manifiesto Lindgren" (Cherchi Usai et al., 2010), como el eco y significación reciente en el polo contrario -en afinidad con el paradigma Langlois- de voces tan autorizadas como la de Dominique Païni, director de la Cinémathèque Royale de Belgique. De la lectura del "Manifiesto Lindgren" extraemos la conclusión de que el legado de Lindgren pervive para el mundo filmotecario conservacionista. En el polo contrario, Païni denuncia cómo la consecuencia de la obsesión con la restauración es "la tendencia actual a monumentalizar la historia del cine y convertirlo en un negocio de antigüedades" (Païni, 1996, p. 8).

Pese a la vigencia de la dicotomía Lindgren-Langlois (Enticknap, 2007), conservación y difusión pueden y deben ser complementarias y alimentarse mutuamente. Las filmotecas deben dar pasos más allá de esta falsa dicotomía y escapar de ella. Si una filmoteca tiene fondos importantes puede propiciar préstamos y canjes para organizar ciclos de proyecciones en colaboración. Y si tiene una relevancia social, generará a su vez interés para que se les realicen depósitos voluntarios que verán en ella una institución viva, abierta y con futuro.

\section{Vectores de expansión del campo filmotecario}

La reflexión sobre qué papel deben jugar las filmotecas en un escenario digital debe atender a los vectores de expansión que se dibujan en la actualidad del campo filmotecario. El primero es el de la accesibilidad. Perdido el pánico a la destrucción del mudo, y aceptada la idea de conservar las obras fundamentales de la cultura cinematográfica, hay que

intensificar las posibilidades de acceso a esos archivos que se abren con los nuevos medios digitales, ya sea a través de canales abiertos como YouTube o Vimeo, por sistemas de video on demand (VOD) para el envío de trabajos más extensos y de menor calidad, o mediante la presencia creciente de las filmotecas en redes sociales, como elemento clave para la difusión de las actividades que desarrollan?

Hoy el patrimonio cultural ya no está integrado sólo por aquello que había sido definido como tal en el pasado. La crisis del objeto, cuya deriva es el acceso al objeto, ha rebajado el deseo de poseer el original y aumentado el deseo de acceder a la copia. La accesibilidad ha pasado de ser un medio a ser el fin último. La misión de las filmotecas debe ser incorporarse hoy a esa ola de accesibilidad, pero salvaguardando los valores de excelencia: el deber que les incumbe y que las diferencia de los agentes de mercado debe ser su preocupación por la calidad, su seriedad, su estética fuerte.

Las filmotecas se encuentran ante la encrucijada de seguir retrocediendo hasta convertirse en un nido de cinéfilos, o de avanzar y tomar algunos territorios de actividad y de presencia social que hasta la fecha parecían reservados a otras entidades

Un segundo vector de expansión lo encontramos en la desaparición del circuito de cineclubs (Hernández-Marcos, 1977) y, más recientemente, de los programas que desarrollan instituciones municipales y educativas. Esta situación está llevando a que las filmotecas, como centro cultural, se constituyan como uno de los escasos lugares donde aún se puede disfrutar de la experiencia cinematográfica en toda su plenitud. Su labor de difusión, que en un principio podía parecer residual respecto al archivo, toma hoy un mayor protagonismo, en un momento en que el hecho cultural del cine en sala va camino de convertirse en un hecho casi museable. 


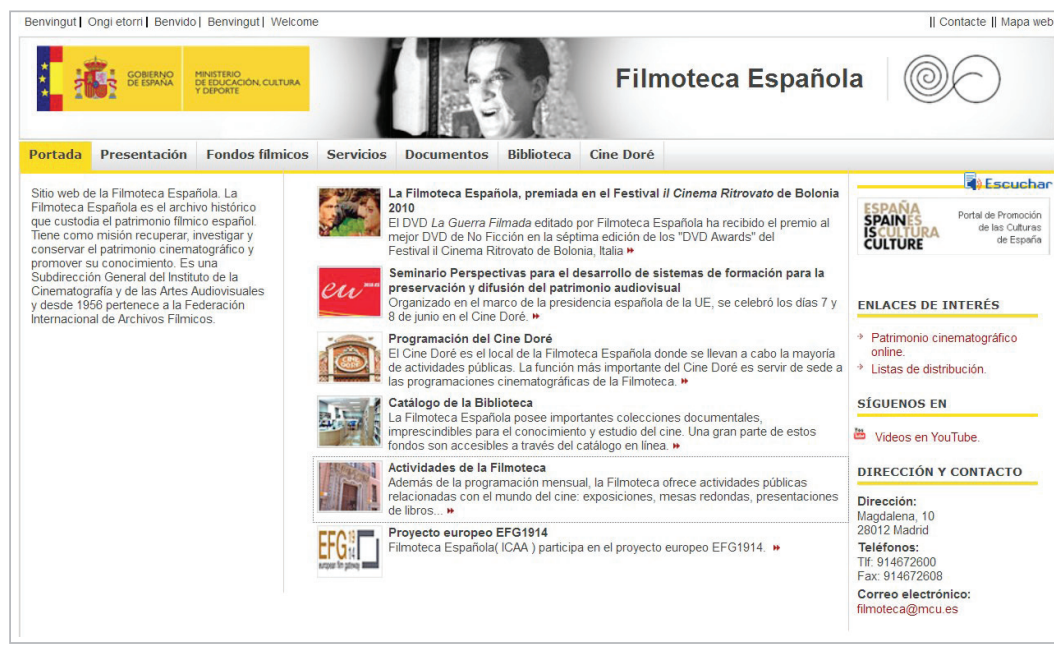

http://www.mcu.es/cine/MC/FE/index.htm/

De hecho, lejos de disminuir el número de espectadores, la mayoría de las filmotecas crecen en los últimos años en número de espectadores ${ }^{8}$. Si se analiza el perfil de la persona que asiste a las sesiones de proyección de la filmoteca, se llegará a la conclusión de que estamos ante un modelo centrado en tres grupos diferenciados: alumnos universitarios, profesionales liberales de formación alta, y lo que podríamos llamar esos "nuevos jubilados" con formación universitaria que ahora disponen de tiempo para poder dedicarse a actividades de ocio y cultura ${ }^{9}$.

Un tercer vector de crecimiento del ámbito de actuación de las filmotecas es el de la vertiente educativa y formativa del cine, alimentado por una carencia histórica en los planes de estudio respecto a la formación audiovisual de los alumnos. Es un campo que tiene dos frentes: el del aprovechamiento del cine como recurso didáctico y el del estricto aprendizaje de los contenidos relacionados con el mundo audiovisual. Y puede tener un campo de actuación desde las primeras edades de infantil hasta la formación postuniversitaria, sin olvidar las posibilidades de formación ocupacional aplicada o las de alfabetización de adultos.

Esta tercera vertiente de expansión alimenta a su vez el número de futuros espectadores de la filmoteca, y es también una manera de mostrar puntualmente a la ciudadanía qué se hace y para qué sirven estas instituciones. Los programas educativos nunca serán un foco noticiable, no tienen el glamour de un estreno y ni siquiera el magnetismo mediático de descubrir o restaurar una película que se creía desaparecida, pero son un elemento de gran potencialidad al pensar en el medio plazo de la defensa futura del patrimonio y de la cultura cinematográfica en la sociedad actual.

\section{Encrucijadas de la actividad filmotecaria en un escenario digital}

El intenso cambio digital que está atravesando el mundo del cine plantea importantes retos de futuro a las filmotecas, a los que deben dar respuesta adecuada para no ahondar en su aislamiento (Schaefer; Streible, 2007). Las filmotecas se encuentran ante la encrucijada de seguir retrocediendo hasta convertirse en un nido de cinéfilos, o de avanzar y to- mar territorios de actividad y de presencia social que hasta la fecha parecían reservados a otras entidades. Un primer ejemplo emblemático de ello surge en el terreno de la exhibición, a partir del debate sobre si resulta filmotecariamente válida la proyección en formatos digitales, asunto sobre el que se ha dialogado de manera muy acalorada en el seno de la FIAF desde dos enfoques contrapuestos (Francis, 2002).

El primero de los enfoques plantea limitar las actividades de las filmotecas a la adquisición, conservación y presentación de las películas producidas en celuloide. Esto limitaría su actividad a un periodo conformado entre el año 1895 y 2025, fecha en la que se estima dejará de usarse el material celuloide por completo (Costa, 2004). Este planteamiento tiene una ventaja pero también un gran inconveniente. La ventaja es que se mantendría incólume la experiencia cinematográfica tal y como se entendía antes de la irrupción del fenómeno digital; pero también acarrea la posibilidad de que la cinematografía no digital sea vista como una experiencia pretérita, y los poderes públicos pierdan paulatinamente el interés por financiar su preservación.

Contrariamente, el segundo enfoque plantea que los archivos no pueden seguir manteniendo sólo la experiencia fílmica original dado el empuje de los avances tecnológicos. Mark-Paul Meyer, investigador principal del EYE Film Institute de Amsterdam, plantea que la identidad e incluso la supervivencia misma de los archivos dependerá de que las filmotecas sean capaces de adaptarse a las nuevas tecnologías. Por ello, es urgente que los archivos fílmicos adopten un rol activo y participativo: no queda otra opción que repensar las políticas de adquisición, de colección, de acceso y hasta de programación. En caso de no ser así la digitalización encerrará aún más a los archivos en sí mismos (Meyer, 2005, p. 9).

\section{Las filmotecas no pueden mantener más la duda sobre si admitir o no la tecnolo- gía digital. Deben asumir el presente (y futuro) digital como una realidad de la que no pueden -ni deben- intentar sus- traerse}

Una nueva encrucijada emblemática a la que se enfrenta la actividad filmotecaria se configura alrededor de la dialéctica "The market vs the museum", una provocación lanzada por Alexander Horwarth en la clausura del $61^{\circ}$ congreso de la FIAF (2005). Para éste nos hallamos actualmente ante un viraje neoliberal en la política global de los archivos de cine al cual es necesario oponerse. Su argumentación está sustentada en el desenmascaramiento de tres términos que han invadido de forma masiva el discurso filmotecario reciente: contenido, acceso y usuario. 
Para Horwarth, pese a que sugieren cosas positivas, como transparencia, actitud antielitista, y aperturismo, se esconde en ellos un menoscabo de las funciones crítica y política de las filmotecas. Por un lado, la palabra 'contenido' (es decir, las colecciones) reemplaza a 'objetos', de la misma manera que la palabra 'producto' desplaza a 'película' en el lenguaje de la industria de Hollywood. En segundo lugar, el acceso significa en la retórica neoliberal esencialmente consumo. Por último, el usuario designa en este nuevo lenguaje a una empresa o proveedor que tiene interés por nuestras colecciones como meros bancos de imágenes.

Pese a que la llamada de atención de Horwarth resulta sin duda útil y necesaria, no creemos que el acceso amplio a las colecciones se oponga a la actividad museal o a la programación crítica, sino que ambas modalidades de acceso deben ser complementarias. Afirmamos, en acuerdo con Nicola Mazzanti, que "debemos aprovechar las posibilidades del mundo digital para el acceso a las colecciones, no debe haber inconveniente alguno en ello, mientras se mantenga una prioritaria política de protección y conservación del patrimonio audiovisual común" (Mazzanti, 2006, p. 10).

Pese a la vigencia de la dicotomía Lindgren-Langlois, conservación y difusión son dos actividades que no tienen por qué ser incompatibles, y pueden y deben ser complementarias y alimentarse mutuamente

Existen numerosos ejemplos de filmotecas que no son ajenas a lo digital actualmente y que están siendo receptivas y realizando nuevos proyectos teniendo en cuenta esta realidad. Además de los casos ya señalados de la Cinémathèque Française, del EYE Film Institute o de la propia Filmoteca Española, destacan asimismo el sistema de accesibilidad y apertura ciudadana a sus fondos del Forum des Images $^{10}$, o el ejemplar sistema de video on demand del British Film Institute ${ }^{11}$, entre otros. Los verdaderos riesgos de la política cultural neoliberal no están en la digitalización misma, sino en que la digitalización se realizara exclusivamente para producciones de entretenimiento, abandonando las posibilidades que se abren para la difusión y la pervivencia de la excelencia cinematográfica.

\section{Conclusiones}

1) A lo largo de la historia las filmotecas respondieron a la barbarie destruccionista de las tres primeras décadas del siglo XX motivadas por los efectos devastadores que la obsolescencia tecnológica tenía para con el patrimonio fílmico. Esa función necesita ser revisada y actualizada ante el nuevo marco digital, dado que nos encontramos ante una auténtica transformación y cambio de paradigma cultural.
2) Las filmotecas no pueden mantener más la duda sobre si admitir o no la tecnología digital. Las filmotecas deben asumir el presente (y futuro) digital como una realidad de la que no pueden -ni deben- intentar sustraerse. Lo digital ya no es el futuro, es el presente, y por tanto deben resolver las dudas respecto a la conservación de esos soportes y de los futuros que se vayan a producir.

3) No basta con ser meros guardianes de los soportes físicos, de las esencias de las emulsiones fotoquímicas. No pueden conformarse con ser meros bancos de imágenes, y deben esforzarse por no encerrarse en cómodas torres de marfil. Las filmotecas necesitan ampliar sus horizontes y constituirse en centros culturales polivalentes, capaces de generar debate, diálogo, reflexión, y un acercamiento menos jerárquico y más participativo a las cuestiones que se generan en las sociedades actuales y que el cine vehicula.

4) Se deben multiplicar las estrategias y vías de acceso digital a colecciones y archivos fílmicos, incluyendo la proyección digital en pantalla grande. Deben ser las propias filmotecas quienes precisen qué estándares de calidad deben tener estas proyecciones, e incumbe a los archivos cinematográficos decidir las ocasiones y condiciones en que una proyección digital pueda reemplazar, como "simulación aceptable" a una proyección cinematográfica.

5) Las filmotecas, en definitiva, no pueden conformarse ni limitarse a defender pasivamente la destrucción de los soportes exclusivamente filmicos. Necesitan dar un paso al frente que les permita alcanzar un marco más amplio de refrendo civil, algo vital en un escenario de cambio intenso como el actual que pone en cuestión los cimientos de lo que ha sido su identidad, función y actividad cultural hasta la fecha.

\section{Notas}

1. En Del-Amo, Alfonso; Fernández, Joxean. Conservación audiovisual en el inicio de la era digital. San Sebastián: Filmoteca Española/Filmoteca Vasca, 2011, pp. 73-78, Luciano Berriatúa despliega todo el debate sobre las maneras y los modos de la restauración fílmica y sobre cómo, con independencia del progreso digital, se debe observar un obliga- 
do respeto por la obra como se gestó en su origen.

2. http://www.dailymotion.com/lacinematheque

3. http://www.instantcinema.org

4. http://www.rtve.es/filmoteca/no-do

\section{5. http://www.youtube.com/user/canalmcu}

6. Los críticos de Cahiers du Cinéma (más tarde los cineastas de la Nouvelle Vague) fueron algunos de esos cinéfilos que se beneficiaban de la generosidad de Langlois, a quien prácticamente santificaron. Basta recordar que el inicio de "Baisers volés" (dirigida por FrançoisTruffaut, 1968) está dedicado al director de la Cinémathèque Française.

7. El crecimiento en seguidores de las actividades de las filmotecas tanto en Facebook como en Twitter resulta exponencial en los últimos años. Sirvan como botón de muestra -sólo en el ámbito hispanoamericano- que a 542.180 personas 'les gusta' la página en Facebook de la Cineteca Nacional de México, a 12.786 personas la de la Cinemateca Brasileira, a 19.163 la de la Cineteca Nacional de Chile, o a 5.826 la de la Filmoteca Española. Igualmente, y sobre las mismos ejemplos, 361.206 personas siguen la cuenta en Twitter de la $C N M, 14.334$ la de la $C B, 32.512$ la de la $C N C H, o 22.080$ la de la propia Filmoteca Española, Ministerio de Cultura [según acceso y consultas de 25 de octubre de 2013].

8. Los datos oficiales estadísticos de la Filmoteca de Andalucía, en la sala de Córdoba, así lo especifican, creciendo desde los 17.016 de 2007 a los 23.172 de 2012.

9. Estos resultados fueron extraídos de un trabajo de campo carácter instrumental realizado por un equipo de trabajadores de la Filmoteca de Andalucía en el mes de febrero de 2009. En esa encuesta también se exponía que un $25 \%$ de los espectadores eran jóvenes con estudios superiores de hasta 25 años, y que existía un importante núcleo (58\%) de público adulto con alto nivel formativo (profesionales y profesores) de 41 a 60 años.

10. El Forum des Images de París ha incorporado recientemente tanto una sala de acceso libre (Salle des Collections) con terminales informáticos con pantallas y sistemas de sonido individualizados que permiten acceder a la práctica totalidad de sus fondos previamente digitalizados, como una WebTV propia con programación continua online.

11. http://www.bfi.org.uk/news-opinion/news-bfi/announcements/ new-video-demand-service-bfi-player-unveiled

\section{Bibliografía}

Beale, Robert (2011). Lindgren \& Langlois: The archive paradox. London: Arts Council England.
http://www.ruthbeale.net/images/Lindgren_Langlois.pdf

Borde, Raymond (1991). Los archivos cinematográficos. Valencia: Ediciones IVAC - Filmoteca de la Generalitat Valenciana. ISBN: 9788478903023

Cherchi-Usai, Paolo et al. The Lindgren manifesto. http://britishlibrary.typepad.co.uk/movingimage/2010/08/ the-lindgren-manifesto.html

Costa, José-Manuel (2004). "Film archives in motion". Journal of film preservation, n. 68, pp. 4-14.

http://www.fiafnet.org/pdf/uk/fiaf68.pdf

Del-Amo, Alfonso; Fernández, Joxean (2011). Conservación audiovisual en el inicio de la era digital. San Sebastián: Filmoteca Española/Filmoteca Vasca, ISBN: 9788493655983

Enticknap, Leo (2007). "Have the digital technologies reopened the Lindgren-Langlois debate?". Spectator, v. 27. n. 1, pp. 10-20.

https://cinema.usc.edu/assets/054/10924.pdf

Francis, David (2002). "Challenges of film archiving in the $21^{\text {st }}$ century". Journal of film preservation, n. 65, pp. 18-24. http://www.fiafnet.org/pdf/uk/04FIAF65.pdf

García-Mangas, Susana (1995). La filmoteca, centro de conservación del cine: el caso español [Tesis doctoral]. Santiago de Compostela: Universidad de Santiago de Compostela.

Gimferrer, Pere (1998). 24 poemas. Barcelona: Plaza y Janés. ISBN: 9788496830974

Hernández-Marcos, José-Luis (1978). Historia de los cineclubs en España. Madrid: Ministerio de Cultura. ISBN: 978 8450025408

Horwartz, Alexander (2005). "The market vs. museum". Journal of film preservation, n. 70, pp. 5-10. http://www.fiafnet.org/pdf/uk/fiaf70.pdf

Mazzanti, Nicola (2006). "Response to Alexander Horwath". Journal of film preservation, n. 70, pp. 10-15. http://www.fiafnet.org/pdf/uk/fiaf70.pdf

Meyer, Mark-Paul (2005). "Traditional film projection in a digital age". Journal of film preservation, n. 70, pp. 15-19. http://www.fiafnet.org/pdf/uk/fiaf70.pdf

Païni, Dominique (1996). “Comme dans un musée”. Journal of film preservation, n. 53, pp. 8-11.

http://www.fiafnet.org/pdf/uk/fiaf53.pdf

Schaefer, Eric; Streible, Dan (2002). “Archival news (Film archives, access, acquisitions, preservation, institutions and organizations)". Cinema journal, v. 42, p. 1, pp. 122-129.

http://www.jstor.org/stable/1225546 